\title{
В. Олышевски
}

\section{ПОЛЬСКИЕ ЭТНОГРАФИЧЕСКИЕ ОТНОШЕНИЯ С СИБИРЬЮ И КАЗАХСТАНОМ С СЕРЕДИНЫ ХІХ ДО НАЧАЛА ХХ В. В КОНТЕКСТЕ РАЗВИТИЯ ТЕОРЕТИЧЕСКОЙ ЭТНОЛОГИИ}

\author{
Исследование выполнено при финансовой поддержке Программы повышения конкурентоспособности ТГУ. \\ Рассматриваются польские этнографические тексты (сообщения польских авторов, поступавшие из Сибири и Казахстана; \\ дневники, воспоминания, описания этих земель и ее жителей), прежде всего литературные памятники, относящиеся к сере- \\ дине XIX - началу XX в., как важный элемент польской национальной этнологии. Несмотря на то что эти источники больше \\ известны российским и казахстанским исследователям, нежели польским читателям, автор акцентирует их значение, прежде \\ всего, в контексте формирования и развития польской идентичности. \\ Ключевые слова: Сибирь; Казахстан; польская этнология; польская идентичность.
}

\section{Сибирь - Казахстан - польская этнология}

Господствующие в польском обществе представления - отчасти научно обоснованные, отчасти вымышленные и фантастические, но так или иначе укоренившиеся на основе научных теорий и знаний, - связывают само пребывание и существование поляков в Сибири с двумя основными мотивами. Первый мотив можно назвать мартирологическим: это память о тех жертвах и тех страданиях, которые перенесли каторжане, ссыльные, принудительно переселенные в Сибирь поляки.

Второй мотив - это память о том вкладе, который сделали поляки в научное исследование Сибири, понимаемой в широком смысле (с охватом Дальнего Востока, Казахстана и других территорий бывшей Российской империи, формирующих общее условное понятие «Сибирь», значительно выходящее за точные, более узкие границы данного географического региона). Нет в этом ничего удивительного, ибо сформировались такие представления в определенном контексте исторических контактов между государством и народом российским, с одной стороны, и государством и народом польским - с другой. Такой взгляд на роль и на само пребывание поляков в Сибири (еще раз подчеркнуСибири, понимаемой в Польше как любое место ссылки в глубины царской или советской империи, расположенное к востоку от Москвы и порою даже совсем близко, не обязательно на Азиатском материке) был важным элементом формирования польской национальной идентичности. Эта идентичность формировалась в определенной оппозиции, в противопоставлении российскому и советскому государству, российской и советской культуре. Не буду останавливаться на этом подробно, тем более потому, что уже не раз приходилось мне это делать, в том числе в выступлениях и публикациях в России [1]. В данной статье я хотел бы сосредоточить внимание на роли научного исследования поляками Сибири, главным образом, в период с середины XIX до начала XX в.
Выбор данного отрезка времени определяется историей польской этнологии. Эта дисциплина в Польше уже в XVIII в. обретала характер сложившейся науки, однако переломным моментом в ее истории (исходным моментом в ее окончательном формировании) считается программа комплексных этнографических исследований, составленная в 1802 г. Гугонем Коллатаем (Hugon Kołątaj), который был ректором Главной королевской школы в Кракове (Ягеллонского университета), доктором философии, теологии и права, историком и одним из создателей антропогеографии. Он занимался проблемами «человеческого рода» (см.: [2. С. 21-24; 3. С. 29-115, 302-309]). Как справедливо заметил один из ведущих историков польской этнологии (культурной антропологии) Збигнев Ясевич (Zbigniew Jasiewicz), «усилившийся в середине XIX века процесс формирования этнологии в качестве самостоятельной научной дисциплины (в Польше. - B.O.) завершился в конце XIX - начале XX века вместе с возникновением институций, в названиях которых уже фигурировали понятия, определяющие данную научную дисциплину, и деятельность которых была направлена на реализацию ее целей» [2. С. 23].

Здесь надо уточнить, что эта научная дисциплина развивалась в то время в Польше в тесной взаимосвязи с этнографией и мировой, в частности российской этнологией, а изучение земель и жителей России воспринималось как естественное изучение страны, в котором полякам, оказавшимся под властью Российской империи, было суждено жить. Сам термин «этнография» в польской печати, вероятно, впервые появился в 1816 г. на страницах «Дженника Виленского» (“Dziennik Wileński”), где была опубликован в переводе с русского на польский язык инструкция для школ 1812 г. [Там же. С. 100].

Первая и единственная до сих пор монография (Sokolewicz), посвященная истории польской этнографии, содержит раздел, в котором рассматриваются место польской этнологии в мировой науке, ее соотношение с другими национальными школами. Этот раздел 
начинается анализом польских сообщений, поступавших из Сибири [4. С. 169-177] ${ }^{1}$. Автор приводит примеры, связанные с работами таких исследователей, как Бронислав Залесский (Bronisław Zaleski), которого российские исследователи никогда не цитировали ${ }^{2}$, а также вспоминает группу ученых, хорошо известных российским и советским исследователям: Александра Чекановского (Aleksandr Czekanowski), Яна Черского (Jan Czerski), Вацлава Серошевского (Wacław Sieroszewski), проводившего исследования среди якутов и айнов; Николая Виташевского (Mikołaj Witaszewski) и Альбина Кохна (Albin Kohn) - участников экспедиции Сибирякова; Бронислава Пилсудского (Bronisław Piłsudski), проводившего свои исследования на Сахалине, а также Юлиана Талько-Гринцевича (Julian Talko-Hryncewicz), работавшего в Забайкалье ${ }^{3}$. Среди польских исследователей Сибири, неизвестных российским ученым, Соколевич называет Марию Чаплицкую (Maria Czaplicka), которая работала и печаталась в Великобритании ${ }^{4}$, а также Станислава Понятовского (Stanisław Poniatowski), чьи материалы, связанные с исследованием Сибири, оставались в рукописях вплоть до 1960-х гг. и никогда не вышли на международную научную орбиту.

Сообщения и научные труды польских исследователей, занимавшихся Сибирью (в широком смысле этого слова) и Казахстаном, были признаны историками польской этнологии (культурной антропологии) как важный вклад в развитие этой научной дисциплины. Несмотря на такую высокую оценку, польским читателям до сих пор непросто с ними познакомиться: наверняка труднее, чем российским или казахстанским читателям. Они редко переиздаются, ощутим острый недостаток таких современных изданий, а старые издания XIX в. остаются труднодоступными, к тому же значительная часть этих работ первоначально публиковалась на русском языке, не все они позднее были переведены на польский язык.

Наиболее повезло в наше время Марии Чаплицкой. В 2013 г. была издана ее книга «Год, прожитый мною в Сибири, или Мой год в Сибири» (перевод на польский c английского оригинала книги «My Siberian Year», изданной в Лондоне в 1916 г.). Эта книга явилась результатом ее поездки в Сибирь в 1914-1915 гг. [6, 7]. Этому исследователю-антропологу, кроме множества статей, посвящены также две книги, в которых ее исследования получили широкое отражение: «Из Оксфорда в Сибирь. Научное наследие Марии Антонинь Чаплицкой» / Z Oxfordu na Syberię. Dziedzictwo naukowe Marii Antoniny Czaplickiej [8] и «Мария Чаплиџкая пол, шаманизм, раса. Антропологическая биография» / Maria Czaplicka - pteć, szamanizm, rasa. Biografia antropologiczna [9]. Значительно раньше - в 1977 г. Витольд Армон (Witold Armon) издал книгу «Польские исследователи якутов» / Polscy badacze Jakutów [10]. Это монография, посвященная научной деятельности Эдварда Пекарского (Edward Piekarski), Бронислава Пилсудского и Вацлава Серошевского. Эта книга не име- ла позднейших переизданий в Польше, зато в 2001 г. она увидела свет в переводе на русский язык в России [11]. Книги, посвященной его научной деятельности, можно сказать, дождался также Северин Гросс (Seweryn Gross) исследователь казахского права [12].

Крупнейший в современной Польше знаток «сибирской полонии» (польского присутствия в Сибири и Казахстане) профессор Антоний Кучинский (Antoni Kuczyński) представил в своей книге «Польское описание мира. О трудах тех, кто познавал культуры других народов и племен» / Polskie opisanie świata. Studia z dziejów poznania kultur ludowych i plemiennych. Tom 1: Azja i Afryka [13. S. 85-174] избранные фрагменты из семнадцати польских донесений и описаний Сибири. Также в изданных под редакцией Антония Кучинского книгах «Сибирь. Четыреста лет польской диаспоры» / Syberia. Czterysta lat polskiej diaspory [14] и «Поляки в Казахстане. Ссылка - наследие - надежды - возвращение» / Polacy w Kazachstanie. Zesłanie - dziedzictwonadzieje - powroty [15] нашли частичное отражение проблемы, связанные с научными исследованиями поляков, с их восприятием Сибири и отношениями с ее жителями.

Добавлю к тому же, что, с одной стороны, современные польские этнологи часто любят подчеркивать симпатию польских исследователей Сибири по отношению к ее коренным народам, а также отмечают то признание значения польских сообщений, какое существует в современных научных и общественных кругах России и Казахстана. Появляются даже специальные публикации, посвященные этим аспектам (например: [16]). С другой стороны, Гражина Кубица (Grażyna Kubica) критикует Марию Чаплицкую за то, что «была она дочерью своего времени и своей науки со всеми добрыми и недобрыми чертами этого времени и этой науки» [5. С. 41], из чего на самом деле следует, что Чаплицкая была способна к критической оценке коренных народов, а в сибирской действительности начала ХХ в. видела не только зло [Там же. С. 40-41].

Итак, существует несомненный диссонанс между декларациями, в которых современные исследователи, занимающиеся проблемами истории польской этнологии, отдают дань текстам (сообщениям из Сибири и Казахстана) авторов XIX в., признают и подчеркивают значение этого научного наследия и крайне ограниченным, почти нулевым использованием этих текстов в современном научном дискурсе и на издальском рынке. В известной мере это нашло отражение в том, что (и как) писал Владислав Барановский (Władysław Baranowski), обращаясь к наследию Юзефа Кобылецкого (Józef Kobyłecki), Эвы Фелинской (Ewa Felińska), Эдварда Островского (Edward Ostrowski), Агатона Гиллера (Agaton Giller), Вацлава Серошевского (Wacław Sieroszewski), Альбины Кохна (Albina Kohna). Он подчеркивал: «Записки польских авторов имеют большое значение как источник сведений о народной культуре жителей Сибири. Это особенно касается периода, кото- 
рый начинается в 1837 г. (в этом году появилась книга Кобылецкого) и простирается до середины 70-х гг. XIX в. Позднее (примерно между 1875 и 1920 гг.) в качестве этнографических источников они теряют свое прежнее значение, во всяком случае, значительно уступают российским текстам (описаниям Сибири) этого времени» [17. С. 271]. Здесь следует обратить внимание на выражение Барановского «в качестве этнографического источника», а также на подзаголовок книги Антония Кучинского «О трудах тех, кто познавал культуры других народов и племен / Studia z dziejów poznania kultur ludowych i plemiennych». Не говорится здесь об истории этнологии или антропологии.

Между тем польская этнология, впрочем, вероятно, как и вся мировая этнология, питалась в свое время многочисленными этнографическими источниками, в том числе текстами (сообщениями с мест) авторовлюбителей (порою снабженных специальными инструкциями), а также трудами представителей смежных наук - географов, историков, языковедов и других, которые обращались к этнографической проблематике как бы на пограничье своей основной профессиональной деятельности. Такие работы печатались в научных и популярных журналах (например, на страницах журналов «Висла / Wisła» и «Люд (Народ) / Lud») рядом со статьями высокого теоретического уровня и глубокого проникновения в этнологическую специфику [2, 3]. Подавляющее большинство текстов польских авторов XIX в. - сообщений о культуре жителей Сибири и других регионов Российской империи - имеет большую ценность как этнографический материал, во многих случаях такой материал, которого не найти ни в каких других источниках. Но этнографический материал это еще не этнология как самостоятельная наука, и даже если в некоторых работах встречались элементы, которые можно считать отражением или проявлением этнологической мысли (теории), в частности размышления, касающиеся этногенеза народов, эволюционизма, антропогеографии, разного рода детерминизмов (причинно-следственных связей), контактов между культурами, а также постулаты о необходимости проведения исследований на языках изучаемых групп населения, - всего этого было еще недостаточно, чтобы внести нечто новое в теоретический дискурс польской этнологии (или вносили эти публикации совсем немного, как, например, труды Талько-Гринцевича, чьи поиски этногенеза народов Сибири были основаны на сочетании и объединении археологического, антропологического и этнографиеского материалов). Самое большее, на что они могли претендовать, - это уровень этнологического рефлекса [4. С. 174-177].

На этом фоне заметно выделяются научные основы трудов таких исследователей, как Станислав Понятовский и Мария Чаплицкая. Первый из них участвовал в работах международного научного коллектива, развивавшего учение российских этнологов Владимира Богораза и Владимира Йохельсона об азиатском проис- хождении американских индейцев. В 1914 г. состоялась связанная с этим проектом, глубоко обоснованная научно и методологически, экспедиция в Сибирь. К сожалению, результаты этой экспедиции не вошли в науку, поскольку Понятовский не обработал и не опубликовал материал проведенных в ходе этой экспедиции исследований: лишь спустя 21 год после его смерти был опубликован его «Дневник экспедищии 1914 года в страну гольдов и орочей» / Dziennik wyprawy (do kraju Goldów i Oroczonów w 1914 r. [4. C. 177].

Экспедиция Марии Чаплицкой - научного сотрудника Оксфордского университета, которая тесно сотрудничала с Генри Холлом (Henry Hall), была организована в результате встречи названных выше российских этнологов с ведущими британскими и американскими антропологами. Эта экспедиция была совместным мероприятием Оксфордского и Пенсильванского университетов. Она прекрасно вписывалась в теоретический дискурс того времени, который развивался в ведущих антропологических центрах. Чаплицкая в Сибири занималась исследованием не только ее коренных народов, главным образом самоедов (ненцев), тунгусов (эвенков) и якутов, но также российских переселенцев и ссыльных. По ее мнению, результатом колонизации Сибири стало формирование новой общности (нового народа) - сибиряков, у которых были все основания стремиться к достижению собственной независимости и к тому, чтобы превратить Сибирь в своего рода «Канаду Востока». Сибирские исследования принесли Марии Чаплицкой признание в научном мире, но это, к сожалению, никак не помогло утверждению ее вклада в науку. В 1921 г. в возрасте 37 лет она покончила собой, и все материалы ее сибирских полевых исследований, которые, согласно завещанию, были посланы Генри Холлу с тем, чтобы он их завершил и обработал, пропали бесследно. Лишь небольшая их часть находится ныне в Pit Rivers Musem [5. С. 34-41].

Неудивительно, что из всех польских исследователей Сибири Чаплицкая представляется сегодня историкам польской этнологии наиболее интересной личностью, выставляемой в Польше напоказ, но и она не сыграла в науке значительной роли.

В контексте всего вышесказанного возникает вопрос, насколько оправдано и обоснованно то большое значение, какое польские этнологи придают польским источникам XIX в. - сообщениям из Сибири и других регионов Российской империи, если эти тексты, можно сказать, никакой роли в развитии теоретической этнологии не сыграли. В известной мере ответ на этот вопрос дает Зофья Соколевич (Zofia Sokolewicz), которая справедливо отмечает, что «авторы этих сообщений описывали то, что бросалось им в глаза как наиболее экзотические явления, отличающиеся от их собственной культуры, религии, мировоззрения. Таким образом, они способствовали не только накоплению значительных запасов ценных источников, но и пробуждению в Польше размышлений над соотношением собственной 
культуры с “чужой” культурой (“чужими” культурами), а такого рода размышления необходимы в процессе формирования этнографии» [4. С. 171].

Мне кажется правильной позиция, сформулированная Зофьей Соколевич (с ней солидарны и другие исследователи), которая заключается в признании того факта, что польско-сибирские отношения более известны (глубже исследованы) в России и в Казахстане, нежели в самой Польше, где им не придают особо важной роли, рассматривая их как этнографический («источниковый») материал, в лучшем случае - как факт из прошлого этнологической науки. Это внимание к прошлому мне понятно, поскольку я разделяю взгляд, согласно которому ученый, а тем более ученыйгуманитарий, не знающий истории своей науки, остается просто невежей. Вернусь в этой связи к тому, что писал в начале данной статьи о формировании польской идентичности. Наука также является тем элементом культуры, который может оказаться важным в процессе формирования национальной идентичности. Так обстоит дело и с теми текстами - описаниями Сибири, сообщениями из Сибири польских авторов позапрошлого века. Для российского исследователя (и жи- теля азиатской части бывшего СССР) эти материалы, если и имеют какое-либо значение, то только в качестве «сырого», чернового материала, этнографического источника или свидетельства тех взглядов, какие были характерны для поляков. Напротив, для нас, поляков, оказывается менее существенным и важным тот этнографический материал, какой содержат в себе данные источники. Мы отдаем себе отчет в том, что они не содействовали теоретическому развитию польской этнологии, а конкурировать с россиянами в исследовании народов Сибири современный польский этнолог не может и не намерен. Гораздо более важным моментом является сама оценка польских исследований учеными и общественностью азиатских регионов России и Казахстана, память о них. Если в польской этнологии культивируется эта память, но нет особенной заботы о том, чтобы содержание всех этих давних сообщений из Сибири стало широко доступным современным читателям, то происходит это, прежде всего, потому, что данный материал важен нам как элемент истории и своеобразия польской этнологии, как элемент истории и формирования национальной идентичности польского народа.

\section{ПРИМЕЧАНИЯ}

\footnotetext{
1 Авторы монографии пользовались термином «этнография», который в Польше еще в $70-\mathrm{x}$ гг. ХХ в. был обязательным в качестве официального названия научной дисциплины. В действительности под этой терминологией уже тогда скрывались университетские исследования и публикации из области этнологии и культурной антропологии. Ныне большинство польских исследователей рассматривают этнографию как часть этнологии, а саму этнологию как науку тождественную (или, по крайней мере, отчасти тождественную) культурной антропологии

${ }^{2}$ Соколевич считает, что работа Залесского «Жизнь киргизских cmeneŭ» / La Vie des Steppes Kirghizes. Descriptions, récits \& contes, изданная в Париже в 1865 г. (Paris, J.-B. Vasseur) уступает по своему качеству более поздним российским исследованиям, чем объясняется отсутствие имени этого ученого в российской историографии [4. С. 172].

3 Это авторский выбор профессора Зофьи Соколевич, которая в своей статье не упоминает целую группу польских исследователей, хорошо известных российским этнологам.

${ }^{4}$ Возможно, Соколевич здесь ошибается. Британская экспедиция в Сибирь, в которой участвовала Чаплицкая, была результатом участия российских этнологов - Владимира (Вальдемара) Йохельсона и Льва Штернберга - в Конгрессе американистов, состоявшемся в 1912 г. в Лондоне. Именно их сообщения об исследованиях, проводимых в Сибири, заинтересовали антропологов Оксфордского университета. С ними, а также с Брониславом Пилсудским, переписывалась Чаплицкая, готовясь к сибирской экспедиции; у нее были контакты и с другими российскими учеными, она знала российские и польские публикации на данную тему [5. С. 15-17].
}

\section{ЛИТЕРАТУРА}

1. Ольшевски В. Исследование польской диаспоры в Сибири. Дилеммы антропологии // Культура русских в археологических исследованиях : сб. науч. ст. Омск ; Тюмень ; Екатеринбург : Магеллан, 2014. С. 34-38.

2. Jasiewicz Z. Początki polskiej etnologii i antropologii kulturowej (od końca XVIII wieku do roku 1918). Poznań : Instytut im. Oskara Kolberga, 2011. $288 \mathrm{~s}$.

3. Posern-Zieliński A. Kształtowanie się polskiej etnografii jako samodzielnej dyscypliny naukowej (do 1939 r.) // Historia etnografii polskiej. Wrocław : Ossolineum, 1973. S. 29-114, 302-309, 326-332.

4. Sokolewicz Z. Miejsce etnografii polskiej w nauce obcej (do 1939 r.) // Historia etnografii polskiej. Wrocław : Ossolineum, 1973. S. 169-192, 313$315,336-337$.

5. Kubica G. Maria Czaplicka i jej syberyjska wyprawa // Czaplicka M. Mój rok na Syberii. Toruń : Muzeum Etnograficzne im. Marii ZnamierowskiejPrüfferowej w Toruniu, 2013. S. 7-42.

6. Czaplicka M.A. My Siberian Year. London : Mills \& Boon, 1916. 315 s.

7. Czaplicka M. Mój rok na Syberii. Toruń : Muzeum Etnograficzne im. Marii Znamierowskiej-Prüfferowej w Toruniu, $2013.195 \mathrm{~s}$

8. Skowron-Markowska S. Z Oksfordu na Syberię. Dziedzictwo naukowe Marii Antoniny Czaplickiej. Wrocław : PTL, 2012. 296 s.

9. Kubica G. Maria Czaplicka: płeć, szamanizm, rasa: biografia antropologiczna. Kraków : Wydawnictwo UJ, 2015.472 s.

10. Armon W. Polscy badacze kultury Jakutów. Wrocław : Zakład Narodowy im. Ossolińskich, 1977. 177 s.

11. Армон В. Польские исследователи культуры якутов. М. : Наука; Интерпериодика, 2001. $172 \mathrm{s.}$

12. Milewska-Młynik A. Seweryn Gross wśród badaczy kazachskiego prawa zwyczajowego. Warszawa : Ludowa Spółdzielnia Wydawnicza, 2012. $255 \mathrm{~s}$.

13. Kuczyński A. Polskie opisanie świata. Studia z dziejów poznania kultur ludowych i plemiennych. T. 1: Azja i Afryka. Wrocław : Wydawnictwo Uniwersytetu Wrocławskiego, 1994. $434 \mathrm{~s}$.

14. Kuczyński A. Syberia. Czterysta lat polskiej diaspory. Wrocław : Dolnośląski Oddział Stowarzyszenia "Wspólnota Polska" we Wrocławiu, 1995. $436 \mathrm{~s}$.

15. Kuczyński A. Polacy w Kazachstanie. Krzeszowice : Wydawnictwo Kubajak, 2014. 544 s. 
16. Lipiński W. Prace polskich badaczy-zesłańców i ich znaczenie we współczesnej Republice Sacha (Jakucja) // Wschód w polskich badaniach etnologicznych i antropologicznych. Problematyka - badacze - znaczenie. Poznań : Biblioteka Telgte/Komitet Nauk Etnologicznych PAN, 2004. S. $215-226$

17. Baranowski W. Polskie relacje o rosyjskiej kulturze ludowej (1831-1920). Łódź : Uniwersytet Łódzki, 1985. 310 s.

Olszewski Wojciech. Nicolaus Copernicus University in Toruń (Toruń, Poland). E-mail: wojol@umk.pl

POLISH ETHNOGRAPHIC ACCOUNTS FROM SIBERIA AND KAZAKHSTAN FROM THE MID-19TH CENTURY TO THE EARLY 20TH CENTURY IN THE CONTEXT OF THE DEVELOPMENT OF ETHNOLOGY.

Key words: Siberia; Kazakhstan; Polish ethnology; Polish identity.

The Polish presence in Siberia, Kazakhstan and other Asian regions of the Russian and Soviet Empire has played an important role in the formation of Polish national identity. Particular emphasis has been put on such aspects of that presence as martyrdom and the contribution of Poles to the scientific study of these territories. Today, Polish ethnographic accounts from the broadly-defined Siberia and from Kazakhstan (especially those written between the mid-19th century and the beginning of the 20th century) are considered an important part of the history of Polish ethnology (cultural anthropology), and their authors are often cited in books and articles on the history of this discipline in Poland. These scholars' achievements, however, are outlined very briefly in most cases, and only selected passages from their accounts are sometimes reprinted. Complete works are not reissued (a notable exception being Maria Czaplicka's My Siberian Year published in English in 1916 and in Polish in 2013). As those researching the history of Polish ethnology admit, Polish ethnographic accounts are better known in Russia or Kazakhstan than in Poland. To explain this situation, one has to point out that Polish ethnology (cultural anthropology) has, from its very beginning, developed in correlation with global ethnology (anthropology). Polish studies conducted in Siberia and Kazakhstan did not make any inspiring contribution in terms of methodological or theoretical development, which is understandable as their authors were often amateurs or representatives of other disciplines, such as geology, geography, history or linguistics. An exception was the research conducted by Maria Czaplicka and Stanisław Poniatowski in the early 20th century in collaboration with leading American, British and Russian scholars, even though this work has gained little or no recognition in Russian and Soviet ethnology. For various reasons, the two ethnologists were unable to finish compiling the results of their research, and therefore their findings never became part of academic discourse. (Maria Czaplicka committed suicide in 1921, and her raw research notes from Siberia - sent to the United States - were lost. As regards Stanisław Poniatowski's Siberian research, only his expedition diary was published more than 20 years after his death). For the above reasons, Polish ethnographic accounts from Siberia and Kazakhstan are only relevant to ethnologists from these parts of the world as raw source material (in the absence of better sources). For Poles, they are part of the history and identity of Polish ethnology (cultural anthropology) and of national identity.

\section{REFERENCES}

1. Olshevski, V. (2014) Issledovanie pol'skoy diaspory v Sibiri. Dilemmy antropologii [The study of the Polish diaspora in Siberia. Dilemmas of anthropology]. In: Tataurova, L.V. (ed.) Kul'tura russkikh v arkheologicheskikh issledovaniyakh [Russian Culture in Archaeological Research]. Omsk; Tyumen; Ekaterinburg: Magellan. pp. 34-38.

2. Jasiewicz, Z. (2011) Początki polskiej etnologii i antropologii kulturowej (od końca XVIII wieku do roku 1918) [The Beginning of Polish Ethnology and Cultural Anthropology (from late 18th century to 1918)]. Poznań: Instytut im. Oskara Kolberga.

3. Posern-Zieliński, A. (1973) Kształtowanie się polskiej etnografii jako samodzielnej dyscypliny naukowej (do 1939 r.) [The formation of Polish Ethnography as an independent science (until 1939)]. In: Sokolewicz, Z. et al. (eds) Historia etnografii polskiej [History of Polish Ethnography]. Wrocław: Ossolineum. pp. 29-114.

4. Sokolewicz, Z. (1973) Miejsce etnografii polskiej w nauce obcej (do 1939 r.) [The place of Polish ethnography in foreign studies (till 1939)]. In: Sokolewicz, Z. et al. (eds) Historia etnografii polskiej [History of Polish Ethnography]. Wrocław: Ossolineum. pp. 169-192.

5. Kubica, G. (2013) Maria Czaplicka i jej syberyjska wyprawa [Maria Czaplicka and her Siberian expedition]. In: Czaplicka, M. Mój rok na Syberii [My Siberian Year]. Torun: Maria Znamierowska-Prüffer Ethnographic Museum in Torun. pp. 7-42.

6. Czaplicka, M.A. (1916) My Siberian Year. London: Mills \& Boon.

7. Czaplicka, M. (2013) Mój rok na Syberii [My Siberian Year]. Toruń: Maria Znamierowska-Prüffer Ethnographic Museum in Torun.

8. Skowron-Markowska, S. (2012) Z Oksfordu na Syberię. Dziedzictwo naukowe Marii Antoniny Czaplickiej [From Oxford to Siberia. The Scientific Heritage of Maria Antonina Czaplicka]. Wrocław: PTL.

9. Kubica, G. (2015) Maria Czaplicka: płeć, szamanizm, rasa: biografia antropologiczna [Maria Czaplicka: Sex, Shamanism, Race: An Anthropological Biography]. Kraków: Wydawnictwo UJ.

10. Armon, W. (1977) Polscy badacze kultury Jakutów [Polish Scholars of Yakut Culture]. Wrocław: Zakład Narodowy im. Ossolińskich.

11. Armon, V. (2001) Pol'skie issledovateli kul'tury yakutov [Polish Researchers of Yakut Culture]. Moscow: Nauka/Interperiodika.

12. Milewska-Młynik, A. (2012) Seweryn Gross wśród badaczy kazachskiego prawa zwyczajowego [Seweryn Gross Among Scholars of Kazakh Common Law]. Warsaw: Ludowa Spółdzielnia Wydawnicza.

13. Kuczyński, A. (1994) Polskie opisanie świata. Studia z dziejów poznania kultur ludowych i plemiennych [Polish Description of the World. The Study of the History of the Folk and Tribal Cultures]. Vol. 1. Wrocław: Wydawnictwo Uniwersytetu Wrocławskiego.

14. Kuczyński, A. (1995) Syberia. Czterysta lat polskiej diaspory [Siberia. Four Hundred Years of Polish Diaspora]. Wrocław: Dolnośląski Oddział Stowarzyszenia "Wspólnota Polska" we Wrocławiu.

15. Kuczyński, A. (2014) Polacy w Kazachstanie [Poles in Kazakhstan]. Krzeszowice: Wydawnictwo Kubajak.

16. Lipiński, W. (2004) Prace polskich badaczy-zesłańców i ich znaczenie we współczesnej Republice Sacha (Jakucja) [The work of Polish expatriates and their significance in contemporary Sakharov (Yakutia)]. In: Jasiewicz, Z. (ed.) Wschód w polskich badaniach etnologicznych i antropologicznych. Problematyka - badacze - znaczenie [East in Polish Ethnological and Anthropological Studies. Issues - Researchers - Significance]. Poznań: Biblioteka Telgte/Komitet Nauk Etnologicznych PAN. pp. 215-226.

17. Baranowski, W. (1985) Polskie relacje o rosyjskiej kulturze ludowej (1831-1920) [Polish Relations on Russian Folk Culture (1831-1920)]. Łódź: Uniwersytet Lódzki. 